\title{
Sex and response of models in observational learning in mice
}

\author{
EZIO SANAVIO and UGO SAVARDI \\ Istituto di Psicologia Sperimentale dell'Universita di Padova, Padova, Italy
}

\begin{abstract}
The present study investigated effects of (1) observing male vs. female models and (2) number of response-relevant cues provided by models. Six groups of male mice were trained to leverpress for water after observing leverpressing responses, drinking responses, or no relevant responses of male or female models. The control group spent time in the observation box without an available model. The subjects paired with models that provided more response-relevant cues learned the fastest; the subjects paired with males performed better than those paired with females. Mice that learned without models were inferior only to the group paired with leverpressing males. A sensory-sensory conditioning hypothesis only partially explains these results.
\end{abstract}

Although observational learning has been demonstrated in several nonprimate species, the relevant controlling variables are much debated (Groesbeck \& Duerfeldt, 1971; Mackintosh, 1974; Mainardi \& Sanavio, 1977). There is evidence that the nature of the observed response affects learning in rats (Kohn \& Dennis, 1972; Sanavio \& Savardi, 1979; Will, Pallaud, Soczka, \& Manikowski, 1974; Zentall \& Levine, 1972). Observation may attract the observer's attention toward the relevant stimuli and facilitate sensory-sensory connections (Bandura, 1969; Del Russo, 1975; Mackintosh, 1974). Of course, the mere presence of a conspecific can lead to an increase in general arousal and general activity, which may result in enhanced emission of dominant rather than novel responses (Gardner \& Engel, 1971; Zajonc, 1965; Zentall \& Levine, 1972). However, removing the models after the observation period and testing subjects alone may provide a means of differentiating observational from social facilitation effects (Del Russo, 1975; Will et al., 1974).

The present experiment was designed to investigate the learning of a leverpressing response after observation of a conspecific that was not present during the leverpressing test. We hypothesized that both the sex of the models and the nature of the response exhibited by the models would affect rate of learning in naive mice.

\section{METHOD}

\section{Subjects}

The experiment was carried out on 100 Swiss-Morini mice, 60-80 days old. Seventy males were used as "pupil" subjects; 15 males and 15 females were used as models. The animals were maintained on a $23 \mathrm{~h}$ water-deprivation schedule, with food continuously available. Animals were randomly assigned to conditions 3 weeks before the experiment, at which time the models were individually trained to leverpress.

Requests for reprints should be sent to Ezio Sanavio, Istituto di Psicologia Sperimentale, p.zza Capitaniato, Padova 35100, Italy.

\section{Apparatus}

Two standard Ralph Gerbrands single-lever operant chambers were used, programmed to provide water reinforcement $(.06 \mathrm{cc})$ on a continous reinforcement basis. To provide an observation box for the pupils, the chambers were modified by inserting a Plexiglas partition that divided each chamber in half.

\section{Procedure}

Subjects were trained to leverpress for water reinforcement in three daily sessions. At the beginning of each session, the subject was placed in the observation box. Following $30 \mathrm{~min}$ of exposure to the assigned condition, the subject was removed and tested alone for $30 \mathrm{~min}$ in the operant chamber.

Three different treatment conditions of the models were designed: (1) "Pressing" models made both instrumental and consummatory responses; that is, they were trained to press the lever and drink from the dipper on a continuous reinforcement schedule. (2) "Drinking" models made only consummatory responses; that is, they were trained to receive free water from the dipper, but presses of the lever had no programmed consequences. (3) "Naive" models made neither instrumental nor consummatory responses; that is, they received no water, and leverpressing had no programmed consequences.

Half of the pupils were paired with male and half with female models of each condition, constituting six observation groups of 10 animals each. Group PM observed pressing males; Group PF observed pressing females; Group DM observed drinking males; Group DF observed drinking females. Group NM observed naive males; and Group NF observed naive females.

A control group (Group W) of 10 subjects spent the 30 -min period before each test session in the observation box without a model in the chamber; that is, they were exposed to an empty apparatus and to a number of dipper clicks like the naive- and drinking-models groups.

The chambers were deodorized by wiping with alcohol between the observation and the test periods; moreover, male and female models alternated in each chamber to balance possible effects arising from persisting pheromone marks.

\section{RESULTS}

A three-way repeated-measures analysis of variance was performed on the number of responses for the six observation groups (Group W was not considered in this analysis) (see Figure 1). The factors were model condition, model sex, and sessions. 


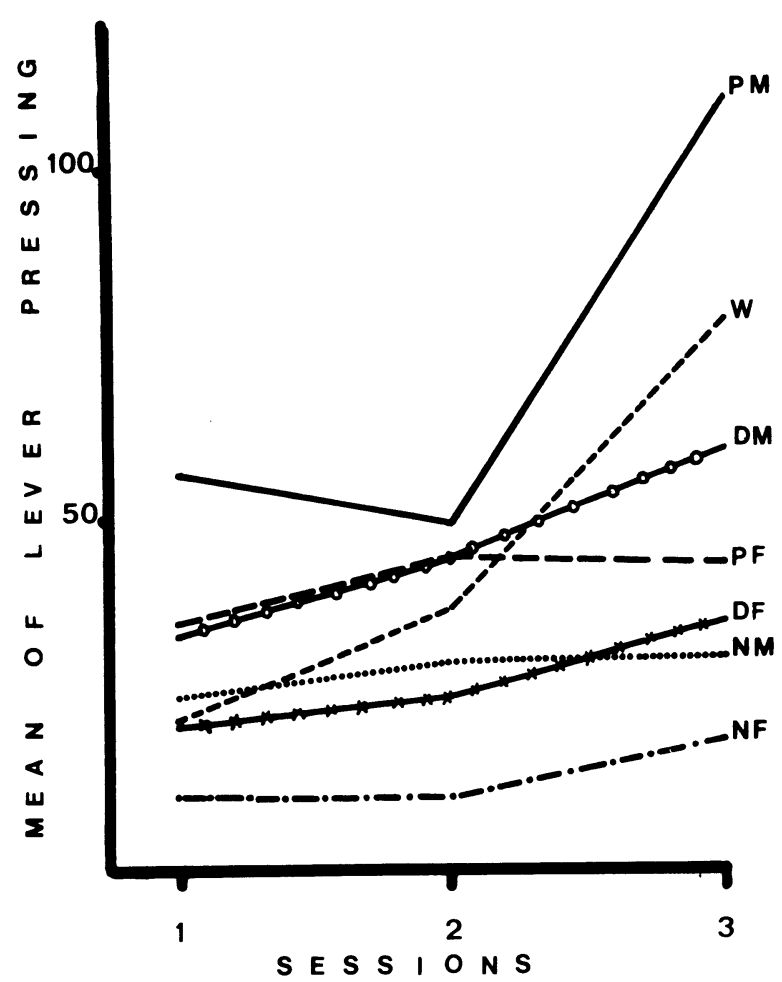

Figure 1. Mean number of leverpresses of the seven groups in each session.

Significant effects were obtained as a function of model condition $[F(2,54)=26.31, p<.001]$. NewmanKeuls post hoc comparisons showed $P$ vs. D $(p<.01)$ and $D$ vs. $N(p<.01)$ to be significant.

The sex of the models also affected subsequent learning by pupils $[F(1,54)=29.31, p<.001]$. Mean total responses were 48.74 for male mice observing male models and 24.79 for male mice observing female models. The primary finding, however, was a reliable triple interaction indicating that the subjects in the various observation groups learned to leverpress at significantly different rates according to characteristics of the models $[F(4,108)=3.85, p<.01]$. Only groups paired with pressing and/or drinking males showed substantial improvement over sessions [Group PM, $\mathrm{F}(4,108)=11.55, \mathrm{p}<.001$; Group DM, $\mathrm{F}(4,108)=2.93$, $\mathrm{p}<.05]$.

Furthermore, subsequent tests of the triple interaction indicated the following differences in Session 3: $\mathrm{PM}>\mathrm{DM} \quad[\mathrm{F}(2,54)=7.30, \mathrm{p}<.01]$, and $\mathrm{DM}>\mathrm{NF}$ $[\mathrm{F}(2,54)=7.87, \mathrm{p}<.01]$.

To investigate the comparison between the control group (Group W) and all other groups, an additional analysis was made, one designed for a factorial experiment with a single control group (Winer, 1970, p. 263). The analysis showed that Group W was inferior to Group PM $(\mathrm{t}=3.66, \mathrm{p}<.001)$ and superior to Group NF $(t=5.41, p<.001)$, but it did not differ from the other groups.

\section{DISCUSSION}

In the present experiment, male mice observed a conspecific for a certain amount of time and had to learn alone to leverpress for water. It is evident from the results that both the nature of the response observed and the sex of the model observed affected the rate of responding of the pupils. Observation of the behavior of a model may facilitate as well as inhibit learning. The one condition in which apparent facilitation was obtained was that in which the pupil observed performing the same response to be learned. Mice that observed male models making instrumental responses (Group PM) learned faster than mice observing only consummatory responses or no responses at all or learning without observation of a model. An inhibitory effect of observing female inactive models was particularly in evidence. In fact, the subjects exposed to naive females learned slower, or did not learn at all, when compared with mice that observed either consummatory plus instrumental responses or only consummatory responses or with mice that learned without models.

Another main finding is that, in the case of male mice pupils, observation of female models produces lower performances than observation of male models.

The present data are consistent with results of Zentall and Levine (1972) in rats and support the sensory-sensory conditioning hypothesis of observational learning (Del Russo, 1975; Mackintosh, 1974). However, distraction or arousing effects may be necessary to explain the decrement due to exposure to female models. If we argue that arousal due to the mere presence of a conspecific persists some time after the removal of the companion, Zajonc's (1965) theory should parsimoniously explain these results. Exposure to naive models may inhibit learning of nondominant responses like leverpressing, while females may be considered highly arousing social companions.

\section{REFERENCES}

Bandura, A. Principles of behavior modification. New York: Holt, 1969.

Des Russo, J. E. Observational learning of discriminative avoidance in hooded rats. Animal Learning \& Behavior, 1975, 3, 76-80.

GARDNER, E. L., \& ENGEL, D. Imitational and social facilitatory aspects of observational learning in the laboratory rat. Psychonomic Science, 1971, 25, 5-6.

Groesbeck, R. W., \& Due RFeldt, H. P. Some relevant variables in observational learning of the rat. Psychonomic Science, 1971, 22, 41-43.

Kohn, B., \& DenNis, M. Observation and discrimination learning in the rat: Specific and nonspecific effects. Journal of Comparative and Physiological Psychology, 1972, 78, 292-296.

Mackintosh, N. J. The psychology of animal learning. London: Academic Press, 1974.

Mainardi, E., \& Sanavio, E. Psicologia dell'apprendimento: Sviluppi e prospettive. Padova: Cleup, 1977.

Sanavio, E., \& Savardi, U. Observational learning of a discriminative shuttlebox avoidance by rats. Psychological Reports, 1979, 44, 1151-1154.

Will, B., Pallaud, B., Soczka, M., \& Manikowski, S. Imitation of leverpressing strategies during the operant conditioning of albino rats. Animal Behaviour, 1974, 22, 664-671.

WINER, B. J. Statistical principles in experimental design. London: McGraw-Hill, 1962.

ZAJONC, R. B. Social facilitation. Science, 1965, 149, 269-274.

Zentall, T. R., \& Levine, J. M. Observational learning and social facilitation in the rat. Science, 1972, 178, 1220-1221.

(Received for publication February 18, 1980.) 